\title{
ANALISIS KADAR NITRIT PADA SOSIS SAPI KEMASAN YANG BEREDAR DI PASAR TRADISIONAL KOTA BANDAR LAMPUNG SECARA SPEKTROFOTOMETRI UV-VIS
}

\section{NITRIT LEVEL ANALYSIS IN PACKAGED BEEF SAUSAGE DISTRIBUTED IN THE TRADITIONAL MARKET OF BANDAR LAMPUNG BY UV-VIS SPECTROPHOTOMETRY}

\author{
Samsuar ${ }^{1}$, Akhmad Rokiban ${ }^{2}$, Dodo Hardoyo ${ }^{3}$ \\ Program Studi Farmasi, Fakultas Matematika dan Ilmu Pengetahuan Alam \\ Universitas Tulang Bawang Lampung \\ Email : samsuar@utb.ac.id \\ HP. 0823-7969-3276
}

\begin{abstract}
The use of nitrite as a preservative and provider of the stable red color, aroma as well as taste for the meat is allowed within processed meat products, such as beef sausage. However, it should be noted that its use does not exceed the maximum permitted limit so as not to negatively impact human health. Excess nitrite in the human body can cause acute poisoning, namely methemoglobinemia and chronic poisoning as a result of the formation of carcinogenic nitrosamine derivatives. This research aims to determine whether the levels of nitrite contained in the packaged beef sausage distributed in the traditional market of Bandar Lampung is in accordance with the regulations of The Indonesia Food and Drug Authority or Indonesia FDA No. 36 of 2013 which is not more than $30 \mathrm{mg} / \mathrm{kg}$. The analysis of nitrite levels in the sample was carried out using with UV-Vis Spectrophotometry method based on diazotation reaction between nitric acid and sulfanilamide forming diazonium salts. The products were then reacted again with naphthyl ethylenediamine to form a purplish red compound whose absorbance was measured at a wavelength of $543,8 \mathrm{~nm}$. From the results of the analytical methods validation, it was obtained that the value of the correlation coefficient was 0,9997, the coefficient of determination 0,9994, the coefficient of variation $1,2121 \%$, the range of percent recovery between $98,630-101,240 \%$, and the detection and the quantitation limit respectively at 0,0187 ppm and 0,0623 ppm. This indicates that all test parameters meet the requirements for their use. The result of determining the average levels of nitrite in the samples show that there were two samples that had levels exceeding the maximum allowed limit, i.e sampel $C=40,407 \mathrm{mg} / \mathrm{kg}$ and sample $D=33,181 \mathrm{mg} / \mathrm{kg}$ while sample $A=18,963 \mathrm{mg} / \mathrm{kg}$, sample $B=9,427 \mathrm{mg} / \mathrm{kg}$, sample $E=9,423 \mathrm{mg} / \mathrm{kg}$ and sample $F=8,689 \mathrm{mg} / \mathrm{kg}$ did not exceed the maximum allowed limit.
\end{abstract}

Keywords: Beef Sausage, Nitrite, UV-Vis Spectrophotometry, Method Analysis Validation

\section{Abstrak}

Penggunaan nitrit sebagai pengawet, pembentuk warna merah daging yang stabil serta pembentuk aroma dan cita rasa diizinkan dalam produk olahan daging, seperti sosis sapi. Akan tetapi, perlu diperhatikan penggunaannya agar tidak melebihi batas maksimum yang diizinkan sehingga tidak berdampak negatif terhadap kesehatan manusia. Kelebihan nitrit dalam tubuh manusia dapat menyebabkan keracunan secara akut, yaitu methemoglobinemia serta keracunan secara kronik akibat dari terbentuknya turunan 


\section{JFL \\ Jurnal Farmasi Lampung

nitrosamin yang bersifat karsinogenik. Penelitian ini bertujuan untuk mengetahui apakah kadar nitrit yang terkandung dalam sosis sapi kemasan yang beredar di pasar tradisional Kota Bandar Lampung sesuai dengan peraturan Kepala BPOM RI No. 36 tahun 2013, yaitu tidak lebih dari $30 \mathrm{mg} / \mathrm{kg}$. Analisis kadar nitrit pada sampel dilakukan dengan metode Spektrofotometri UV-Vis yang didasarkan pada reaksi diazotasi antara asam nitrit dengan sulfanilamid membentuk garam diazonium, selanjutnya direaksikan kembali dengan naftiletilendiamin membentuk senyawa berwarna merah keunguan dan diukur absorbansinya pada panjang gelombang $543,8 \mathrm{~nm}$. Hasil dari validasi metode analisis diperoleh nilai koefisien korelasi 0,9997, koefisien determinasi 0,9994, koefisien variasi $1,2121 \%$, rentang persen perolehan kembali berkisar antara 98,630-101,240\%, batas deteksi dan batas kuantitasi masing-masing 0,0187 ppm dan 0,0623 ppm. Hal ini menunjukkan bahwa semua parameter uji memenuhi persyaratan untuk penggunaannya. Hasil dari penentuan kadar rata-rata nitrit pada sampel menunjukkan bahwa terdapat dua sampel yang memiliki kadar melebihi batas maksimum yang diizinkan, yaitu sampel $C=40,407 \mathrm{mg} / \mathrm{kg}$ dan sampel $D=33,181 \mathrm{mg} / \mathrm{kg}$ sedangkan sampel $A=18,963 \mathrm{mg} / \mathrm{kg}$, sampel $B=9,427 \mathrm{mg} / \mathrm{kg}$, sampel $E=9,423 \mathrm{mg} / \mathrm{kg}$ dan sampel $F=8,689 \mathrm{mg} / \mathrm{kg}$ memiliki kadar nitirit yang tidak melebihi batas maksimum yang diizinkan.

Kata kunci : Sosis sapi, Nitrit, Spektrofotometri UV-Vis, Validasi metode analisis

\section{PENDAHULUAN}

Era globalisasi sekarang ini, banyak masyarakat yang menginginkan sesuatu secara instan, contohnya makanan cepat saji. Pola hidup masyarakat untuk mengkonsumsi makanan cepat saji sudah menjadi kebiasaan, dapat dilihat dari persentase perolehan data yang ada dengan tingkat kebiasaan konsumsi makanan cepat saji sebesar $67,6 \%$, sedangkan persentase responden yang mempunyai alasan memilih makanan cepat saji lebih praktis sebesar $73 \%$ dan karena alasan enak sebesar 27\%(1). Makanan siap saji yang saat ini digemari masyarakat salah satunya sosis sapi. Sosis Sapi merupakan produk olahan berbahan baku daging sapi yang memiliki nilai gizi tinggi, berbentuk silindris dengan panjang kira-kira $8-10 \mathrm{~cm}$, bukan hanya digemari oleh anak-anak dan remaja bahkan orang tua juga menyukainya(2).

Daging sapi sebagai bahan baku utama dalam pembuatan sosis sapi dapat mengalami kerusakan yang disebabkan oleh mikroorganisme perusak dan atau patogen yang dapat menyebabkan pembusukan dan atau penyakit, mengalami perubahan warna dan mengalami penurunan cita rasa. Oleh karena itu, dalam proses pembuatan produk olahan daging, seperti sosis sapi biasanya ditambahkan bahan tambahan makanan yang bertujuan untuk mengatasi masalah tersebut(3).

Nitrit merupakan salah satu bahan tambahan makanan yang digunakan pada pembuatan sosis sapi yang berfungsi sebagai pengawet untuk menghambat pertumbuhan mikroorganisme pembusuk dan atau patogen seperti bakteri Clostridium botullinum, untuk mempertahankan warna merah daging agar tetap stabil serta sebagai pembentuk faktor sensori lain, yaitu cita rasa dan aroma(3).

Penggunaan nitrit sebagai pengawet dalam makanan diizinkan, akan tetapi perlu diperhatikan agar tidak melebihi batas maksimum yang diizinkan sehingga tidak berdampak negatif terhadap kesehatan manusia sesuai dengan peraturan Kepala Badan Pengawasan Obat dan Makanan Republik Indonesia No. 36 tahun 2013 tentang batas maksimum penggunaan bahan tambahan pangan pengawet nitrit pada produkproduk olahan daging, daging unggas dan daging hewan buruan yang dihaluskan, yaitu tidak lebih dari $30 \mathrm{mg} / \mathrm{kg}(4)$. Sedangkan batas maksimum kadar nitrit yang boleh masuk kedalam tubuh adalah 
0-0,06 $\mathrm{mg} / \mathrm{kg}$ BB yang telah disesuaikan dengan kadar Acceptable Daily Intake (ADI), yaitu asupan harian yang dapat diterima atau jumlah maksimum bahan tambahan pangan yang dapat dikonsumsi setiap harinya, bahkan selama hidupnya tanpa menimbulkan efek merugikan terhadap kesehatan(5).

Kelebihan nitrit dalam tubuh manusia dapat menyebabkan keracunan secara akut, yaitu methemoglobinemia. Methemoglobinemia adalah suatu kondisi darah yang mengandung methemoglobin, yaitu hemoglobin yang mengandung ion besi trivalen $\left(\mathrm{Fe}^{3+}\right)$ hasil dari reaksi nitrit dengan hemoglobin yang mengoksidasi besi divalen $\left(\mathrm{Fe}^{2+}\right)$ menjadi besi trivalen $\left(\mathrm{Fe}^{3+}\right)$. Methemoglobin tidak dapat mengikat oksigen sehingga menyebabkan kekurangan oksigen didalam darah (hypoxia) yang ditandai dengan wajah menjadi pucat, kulit membiru (cianosis), sesak napas, muntah dan shock bahkan kematian dapat terjadi jika kadar methemoglobin dalam darah mencapai $70 \%$ atau lebih(6).

Keracunan secara kronis juga dapat terjadi akibat dari terbentuknya turunan nitrosamin yang bersifat karsinogenik. Turunan nitrosamin dapat terbentuk akibat reaksi antara nitrit dengan amina sekunder. Nitrosamin dapat menyebabkan kanker pada berbagai organ tubuh, seperti hati, ginjal, kandung kemih, paru-paru, lambung, saluran pernapasan, pankreas dan lain-lain(5).

Hasil penelitian Romsiah (2017), tentang validasi metode dan penetapan kadar nitrit pada sosis sapi curah dan sosis sapi kaleng yang dijual di swalayan kota Palembang secara spektrofotometri UVVis menunjukkan bahwa dari 6 sampel yang dianalisis terdapat 2 sampel yang mengandung nitrit melebihi batas maksimum yang diizinkan sesuai dengan peraturan Kepala BPOM RI No. 36 tahun 2013, yaitu sampel $A=77,36 \mathrm{mg} / \mathrm{kg}$ dan sampel $B=82,38 \mathrm{mg} / \mathrm{kg}$ sedangkan sampel C, I, II dan III mengandung nitrit yang tidak melebihi batas maksimum yang diizinkan, yaitu 26,76 mg/kg; 5,81 mg/kg; $5,03 \mathrm{mg} / \mathrm{kg}$ dan 6,91 mg/kg(7).

Berdasarkan latar belakang tersebut, maka peneliti terdorong untuk melakukan analisis kadar nitrit pada sosis sapi kemasan yang beredar di pasar tradisional Kota Bandar Lampung secara spektrofotometri uv-vis yang telah divalidasi sebelumnya.

\section{METODE PENELITIAN}

\section{Waktu dan Tempat Penelitian}

Penelitian dilakukan pada bulan September dan Oktober tahun 2019 di Unit Pelaksana Teknis Dinas (UPTD) Balai Laboratorium Kesehatan Provinsi Lampung.

\section{Alat dan Bahan}

Alat-alat yang digunakan dalam penelitian ini adalah Spektrofotometer UV-Vis (Shimadzu $^{\circledR}$ UV-1800), neraca analitik $\left(\right.$ Shimadzu $\left.{ }^{\circledR}\right)$, batang pengaduk, spatula, mortier dan stamper, penangas air/water bath $\left(\right.$ Memmert $\left.^{\circledR}\right)$, Labu ukur (Pyrex ${ }^{\circledR}$ ), Gelas ukur $\left(\right.$ Pyrex $\left.^{\circledR}\right)$, erlenmeyer $\left(\right.$ Pyrex $\left.^{\circledR}\right)$, gelas piala $\left(\right.$ Pyrex $\left.^{\circledR}\right)$, pipet volumetrik $\left(\right.$ Pyrex $\left.^{\circledR}\right)$, corong kaca $\left(\right.$ Pyrex $\left.^{\circledR}\right)$, botol semprot, kertas saring, lemari asam, lemari penyimpanan larutan pereaksi (GEA), stopwatch, spidol dan kertas label.

Bahan-bahan yang digunakan dalam penelitian ini adalah sampel sosis sapi kemasan dari pasar tradisional, sulfanilamid $\left(\mathrm{C}_{6} \mathrm{H}_{8} \mathrm{~N}_{2} \mathrm{O}_{2} \mathrm{~S}\right)$ p.a (Merck), naftiletilendiamin $\left(\mathrm{C}_{12} \mathrm{H}_{14} \mathrm{~N}_{2}\right)$ p.a (Merck), natrium nitrit $\left(\mathrm{NaNO}_{2}\right)$ p.a (Merck), asamasetat $\left(\mathrm{CH}_{3} \mathrm{COOH}\right)$ p.a (Merck), asam klorida $(\mathrm{HCl})$ p.a dan aqua demineralisata (PT. Brataco).

\section{Prosedur Penelitian}

\section{Pengambilan Sampel}

Sampel sosis sapi kemasan diambil dari pasar tradisional kota Bandar Lampung, diperoleh 5 sampel dengan merk yang berbeda dari 5 pasar tradisional yang berbeda pula, yaitu sampel A (Pasar 
Koga), sampel B (Pasar Ambon), sampel D (Pasar Tugu), sampel E (Pasar Perumnas Way Halim) dan sampel $F$ (Pasar Tempel Way Dadi) dan terdapat 1 sampel dengan merk yang sama yang dijual di 4 pasar tradisional yang berbeda, yaitu sampel $C$ yang terdapat di Pasar Panjang, Pasar Ambon, Pasar Tugu dan Pasar Koga. Untuk sampel yang bermerk sama, pengambilan sampel dilakukan dengan teknik simple random sampling, yaitu teknik pengambilan sampel secara acak sederhana, dimana pengambilan sampelnya dilakukan secara acak dari populasi sampel yang sejenis atau homogen sehingga memiliki kesempatan yang sama untuk diambil sebagai sampel uji. Selanjutnya sampel yang sejenis atau homogen tersebut ditentukan dengan cara undian sehingga setiap unit mempunyai peluang yang sama untuk dapat terpilih sebagai sampel uji(9).

\section{Preparasi Sampel}

Masing-masing sampel ditimbang menggunakan neraca analitik sebanyak $25 \mathrm{~g}$ kemudian dihaluskan menggunakan mortier dan stamper. Sampel-sampel yang telah dihaluskan tersebut kemudian ditimbang menggunakan neraca analitik sebanyak $5 \mathrm{~g}(10)$. Analisis kadar nitrit dalam sampel dilakukan secara triplo, yaitu pengukuran dilakukan sebanyak 3 kali pengulangan sehingga penimbangan masing-masing sampel dilakukan sebanyak 3 kali. Hal ini bertujuan untuk mengetahui tingkat ketelitian atau presisi pengukuran, meningkatkan keabsahan hasil analisis serta untuk menentukan kadar rata-rata nitrit yang terkandung dalam masing-masing sampel(11). Selanjutnya masing-masing sampel yang telah ditimbang tersebut dimasukkan kedalam masing-masing wadah plastik klip yang telah diberi label.

\section{Pembuatan Larutan Pereaksi}

a. Larutan asam asetat $\left(\mathrm{CH}_{3} \mathrm{COOH}\right) 15 \%$ $(\mathrm{v} / \mathrm{v})$

Dipipet sebanyak $75 \mathrm{~mL}$ asam asetat $100 \%$ kemudian dimasukkan kedalam labu ukur $500 \mathrm{~mL}$ dan ditambahkan aqua demineralisata sampai tanda batas.

b. Pereaksi Sulfanilamid

Ditimbang dalam gelas piala sebanyak $0,5 \mathrm{~g}$ sulfanilamid p.a menggunakan neraca analitik lalu dilarutkan kedalam $150 \mathrm{~mL}$ asam asetat 15\% (v/v) kemudian larutan disaring dan disimpan dalam botol berwarna coklat(12).

c. Pereaksi Naftiletilendiamin

Ditimbang dalam gelas piala sebanyak $0,2 \mathrm{~g}$ naftiletilendiamin dihidroklorida p.a menggunakan neraca analitik lalu dilarutkan kedalam $150 \mathrm{~mL}$ asam asetat $15 \% \quad(\mathrm{v} / \mathrm{v})$ kemudian larutan disaring dan disimpan dalam botol berwarna coklat(12).

\section{Pembuatan Larutan Baku Natrium Nitrit}

Ditimbang sebanyak $1,0 \mathrm{~g}$ natrium nitrit p.a kemudian dimasukkan kedalam labu ukur $1000 \mathrm{~mL}$ lalu ditambahkan aqua demineralisata sampai tanda batas sehingga diperoleh kosentrasi 1000 ppm. Dari larutan baku natrium nitrit 1000 ppm, dipipet $10 \mathrm{~mL}$ kemudian dimasukkan kedalam labu ukur $100 \mathrm{~mL}$ lalu ditambahkan aqua demineralisata sampai tanda batas sehingga diperoleh kosentrasi 100 ppm. Dari larutan baku natrium nitrit 100 ppm, dipipet $10 \mathrm{~mL}$ kemudian dimasukkan kedalam labu ukur $100 \mathrm{~mL}$ lalu ditambahkan aqua demineralisata sampai tanda batas sehingga diperoleh kosentrasi $10 \mathrm{ppm}$. Dari larutan baku natrium nitrit $10 \mathrm{ppm}$, dipipet $10 \mathrm{~mL}$ kemudian dimasukkan kedalam labu ukur $100 \mathrm{~mL}$ lalu ditambahkan aqua demineralisata sampai tanda batas sehingga diperoleh kosentrasi 1 ppm(12).

\section{Pembuatan Larutan Seri Konsentrasi Baku Natrium Nitrit}

Semua larutan seri konsentrasi baku natrium nitrit dibuat dengan cara 
pengenceran dari larutan baku natrium nitrit 10 ppm sebanyak $50 \mathrm{~mL}(10)$.

Dipipet $45 \mathrm{~mL}$ aqua demineralisata kemudian dimasukkan kedalam labu ukur $50 \mathrm{~mL}$ lalu ditambahakan $2,5 \mathrm{~mL}$ pereaksi sulfanilamid dan $2,5 \mathrm{~mL}$ pereaksi naftiletilendiamin sehingga diperoleh larutan branko(12).

Dari larutan baku natrium nitrit $10 \mathrm{ppm}$ dipipet sebanyak 0,$5 ; 1,0 ; 1,5 ; 2,0 ; 2,5$; 3,$0 ; 3,5 ; 4,0 ; 4,5$ dan $5,0 \mathrm{~mL}$ kemudian dimasukkan kedalam labu ukur $50 \mathrm{~mL}$ lalu ditambahkan aqua demineralisata sampai tanda batas sehingga diperoleh larutan seri konsentrasi baku 0,$1 ; 0,2 ; 0,3 ; 0,4$; 0,$5 ; 0,6 ; 0,7 ; 0,8 ; 0,9$ dan 1 ppm.

\section{Penentuan Panjang Gelombang Maksimum Larutan Baku Natrium Nitrit}

Dipipet $10 \mathrm{~mL}$ larutan seri konsentrasi baku natrium nitrit $0,7 \mathrm{ppm}$ kemudian dimasukkan ke dalam labu ukur $50 \mathrm{~mL}$ lalu ditambahkan $1 \mathrm{~mL}$ pereaksi sulfanilamid dan digoyangkan, setelah 5 menit ditambahkan $1 \mathrm{~mL}$ pereaksi naftiletilendiamin dan digoyangkan lagi kemudian diencerkan dengan aqua demineralisata sampai tanda batas dan dikocok, selanjutnya larutan dibiarkan selama 15 menit sampai terbentuk warna merah keunguan yang konstan. Selanjutnya masukkan larutan uji kedalam kuvet Spektrofotometer UV-Vis kemudian diukur absorbansinya pada rentang panjang gelombang 490-590 nm sehingga diperoleh panjang gelombang yang memberikan absorbansi maksimum(10).

\section{Penentuan Operating Time}

Dipipet $10 \mathrm{~mL}$ larutan seri konsentrasi baku natrium nitrit $0,7 \mathrm{ppm}$ kemudian dimasukkan kedalam labu ukur $50 \mathrm{~mL}$ lalu ditambahkan $1 \mathrm{~mL}$ pereaksi sulfanilamid dan digoyangkan, setelah 5 menit $\begin{array}{llll}\text { ditambahkan } & 1 & \mathrm{~mL} & \text { pereaksi }\end{array}$ naftiletilendiamin dan digoyangkan lagi kemudian diencerkan dengan aqua demineralisata sampai tanda batas dan dikocok, selanjutnya larutan dibiarkan selama 15 menit sampai terbentuk warna merah keunguan yang konstan. Selanjutnya masukkan larutan uji kedalam kuvet Spektrofotometer UV-Vis dan diukur absorbansinya pada panjang gelombang maksimum setiap menit ke 6,9,12,15 dan 18 lalu ditentukan operating time-nya(10).

\section{Uji Parameter Validasi Metode Analisis}

\section{a. Uji Ketelitian atau Keseksamaan} (Precision)

Dipipet $10 \mathrm{~mL}$ filtrat sampel A sebanyak 6 kali kemudian dimasukkan kedalam 6 labu ukur $50 \mathrm{~mL}$ lalu ditambahkan $1 \mathrm{~mL}$ pereaksi sulfanilamid kedalam masingmasing sampel dan digoyangkan, setelah 5 menit ditambahkan $1 \mathrm{~mL}$ pereaksi naftiletilendiamin kemudian dikocok dan dibiarkan selama 15 menit sampai terbentuk warna merah keunguan yang konstan. Masukkan larutan uji kedalam kuvet Spektrofotometer UV-Vis kemudian diukur absorbansinya pada panjang gelombang maksimum 543,8 nm dan operating time menit ke-12, selanjutnya dihitung nilai simpangan baku dan simpangan baku relatif atau koefisien variasinya(10).

\section{b. Uji Linieritas (Linierity) dan Rentang (Range) serta Pembuatan Kurva Kalibrasi dan Penentuan Persamaaan Regresi Linier}

Dipipet $10 \mathrm{~mL}$ larutan blanko dan $10 \mathrm{~mL}$ masing-masing larutan seri konsentrasi baku natrium nitrit 0,$1 ; 0,2 ; 0,3 ; 0,4 ; 0,5$; 0,$6 ; 0,7 ; 0,8 ; 0,9$ dan 1 ppm kemudian dimasukkan kedalam masing-masing labu ukur $50 \mathrm{~mL}$, selanjutnya masing-masing larutan ditambahkan $1 \mathrm{~mL}$ pereaksi sulfanilamid dan digoyangkan, setelah 5 menit ditambahkan $1 \mathrm{~mL}$ pereaksi naftiletilendiamin kemudian digoyangkan lagi lalu diencerkan dengan aqua demineralisata sampai tanda batas kemudian dikocok dan dibiarkan selama 15 menit sampai terbentuk warna merah keunguan yang konstan. Masukkan larutan uji kedalam kuvet Spektrofotometer UV-Vis kemudian diukur absorbansinya pada panjang gelombang 
maksimum 543,8 $\mathrm{nm}$ dan operating time menit ke-12. Dihitung nilai koefisien korelasi $(r)$ dan koefisien determinasi $\left(R^{2}\right)$.

Dari hasil uji linieritas dan rentang (daerah kerja) larutan seri konsentrasi baku natrium nitrit tersebut, selanjutnya dibuat kurva kalibrasi (kurva baku) hubungan antara konsentrasi dan absorbansi natrium nitrit kemudian dihitung nilai koefisien regresi/slope (b) dan konstanta/intersep (a) sehingga diperoleh persamaan garis $y=b x+a(13)$.

\section{c. Uji Ketepatan(Accuracy)}

Ditimbang sampel A yang telah dihaluskan sebanyak $5 \mathrm{~g}$ kemudian dimasukkan kedalam erlenmeyer $50 \mathrm{~mL}$ lalu ditambahkan $40 \mathrm{~mL}$ aqua demineralisata yang telah dipanaskan sampai suhu $80^{\circ} \mathrm{C}$, diaduk dengan pengaduk kaca kemudian dipindahkan kedalam labu ukur $500 \mathrm{~mL}$, bilas erlenmeyer dengan aqua demineralisata panas, tuangkan kedalam labu ukur, selanjutnya ditambahkan aqua demineralisata panas sampai volumenya lebih kurang $300 \mathrm{~mL}$ kedalam labu ukur kemudian dipanaskan pada penangas air selama 2 jam pada suhu $80^{\circ} \mathrm{C}$ sambil sesekali digoyangkan. Diangkat labu ukur dari penangas air kemudian ditambahkan $6 \mathrm{~mL}$ asam klorida kedalam larutan sampel dan digoyang-goyangkan pada suhu kamar lalu diencerkan dengan aqua demineralisata sampai tanda batas kemudian dikocok lalu disaring sebanyak 2 kali menggunakan kertas saring. Dipipet $10 \mathrm{~mL}$ filtrat sampel A sebanyak 5 kali kemudian dimasukkan kedalam labu ukur $50 \mathrm{~mL}$. Untuk penambahan larutan adisi standar, dipipet sebanyak $10 \mathrm{~mL}$ larutan baku natrium nitrit 0,$15 ; 0,225 ; 0,3 ; 0,375$ dan 0,45 ppm kemudian ditambahkan kedalam filtrat sampel. Ditambahkan $1 \mathrm{~mL}$ pereaksi sulfanilamid dan digoyangkan, setelah 5 menit ditambahkan $1 \mathrm{~mL}$ pereaksi naftiletilendiamin kemudian dikocok dan dibiarkan selama 15 menit sampai terbentuk warna merah keunguan yang konstan. Masukkan larutan uji kedalam kuvet Spektrofotometer UV-Vis kemudian diukur absorbansinya pada panjang gelombang maksimum $543,8 \mathrm{~nm}$ dan operating time menit ke-12(7). Dihitung nilai persen perolehan kembali (\% recovery) analit yang ditambahkan dengan rumus sebagai berikut(8):

$$
\% \text { recovery }=\frac{\mathrm{C}_{1}-\mathrm{C}_{2}}{\mathrm{C}_{3}} \times 100 \%
$$

Keterangan:

$\mathrm{C}_{1}$ : Konsentrasi analit dalam campuran sampel dan analit yang ditambahkan

$\mathrm{C}_{2}$ : Konsentrasi analit dalam sampel

$\mathrm{C}_{3}$ : Konsentrasi analit yang ditambahkan

\section{d. Uji Batas Deteksi (Limit of Detection) dan Batas Kuantitasi (Limit of Quantitation)}

Penentuan nilai batas deteksi dan batas kuantitasi dihitung secara statistik melalui garis regresi linier dari kurva baku (kurva kalibrasi) larutan seri konsentrasi baku natrium nitrit 0,0-0,7 ppm. Simpangan baku blanko sama dengan simpangan baku residual(13).

\section{Analisis Kuantitatif Natrium Nitrit}

Ditimbang masing-masing sampel yang telah dihaluskan sebanyak $5 \mathrm{~g}$ kemudian dimasukkan kedalam erlenmeyer $50 \mathrm{~mL}$ lalu ditambahkan $40 \mathrm{~mL}$ aqua demineralisata yang telah dipanaskan sampai suhu $80^{\circ} \mathrm{C}$, diaduk dengan pengaduk kaca kemudian dipindahkan kedalam labu ukur $500 \mathrm{~mL}$. Bilas erlenmeyer dengan aqua demineralisata panas lalu dituangkan kedalam labu ukur, tambahkan aqua demineralisata panas hingga labu ukur terisi lebih kurang 300 $\mathrm{mL}$, kemudian dipanaskan pada penangas air selama 2 jam pada suhu $80^{\circ} \mathrm{C}$ sambil sesekali digoyangkan. Didinginkan sampai suhu kamar lalu diencerkan dengan aqua demineralisata sampai tanda batas, kemudian dikocok dan disaring sebanyak 2 kali menggunakan kertas saring dengan erlenmeyer terpisah. Pipet filtrat sampel sebanyak $10 \mathrm{~mL}$ kemudian dimasukkan kedalam labu ukur $50 \mathrm{~mL}$. Ditambahkan 2,5 $\mathrm{mL}$ pereaksi sulfanilamid kemudian digoyangkan, setelah 5 menit 
ditambahkan $2,5 \quad \mathrm{~mL}$ pereaksi naftiletilendiamin kemudian digoyangkan lagi, lalu diencerkan dengan aqua demineralisata sampai tanda batas, kemudian dikocok dan dibiarkan selama 15 menit sampai terbentuk warna merah keunguan yang konstan. Masukkan larutan sampel kedalam kuvet Spektrofotometer UV-Vis, dan diukur absorbansinya pada panjang gelombang maksimum 543,8 $\mathrm{nm}$ dan operating time menit ke-12(12). Dihitung konsentrasi dan kadar natrium nitrit serta kadar nitrit dalam masing-masing sampel menggunakan rumus sebagai berikut(14):

$\operatorname{Kadar} \mathrm{NaNO}_{2}=\frac{\mathrm{c} \mathrm{x} \mathrm{v}}{\mathrm{w}} \times f(\mathrm{mg} / \mathrm{kg})$

Kadar $\mathrm{NO}_{2}{ }^{-}=\frac{\mathrm{BM} \mathrm{NO}_{2}^{-}}{\mathrm{BM} \mathrm{NaNO}_{2}} \times$ Kadar $\mathrm{NaNO}_{2}$

Keterangan:

C : Konsentrasi natrium nitrit dalam sampel (mg/L)

$\checkmark$ : Jumlah saringan yang digunakan untuk penetapan kadar (L)

$f \quad$ : Faktor pengenceran

w : Massa sampel yang diambil $(\mathrm{Kg})$

BM : Berat molekul

\section{HASIL DAN PEMBAHASAN}

\section{Hasil Penentuan Panjang Gelombang Maksimum}

Penentuan panjang

gelombang maksimum dilakukan dengan cara membuat kurva hubungan antara absorbansi dengan rentang panjang gelombang tertentu dari satu larutan baku pada konsentrasi tertentu(11).

Tabel 1. Hasil penentuan panjang gelombang maksimum larutan seri konsentrasi baku natrium nitrit 0,7 ppm

\begin{tabular}{|c|c|c|}
\hline No & $\begin{array}{c}\text { Panjang } \\
\text { Gelombang } \\
\text { (nm) }\end{array}$ & Absorbansi \\
\hline 1 & 496,80 & 0,501 \\
\hline 2 & 516,20 & 0,508 \\
\hline 3 & 518,20 & 0,510 \\
\hline
\end{tabular}

\begin{tabular}{|c|c|c|}
\hline 4 & 520,60 & 0,521 \\
\hline 5 & 528,40 & 0,603 \\
\hline 6 & 534,80 & 0,672 \\
\hline $\mathbf{7}$ & $\mathbf{5 4 3 , 8 0}$ & $\mathbf{0 , 7 4 0}$ \\
\hline 8 & 547,20 & 0,735 \\
\hline 9 & 555,40 & 0,650 \\
\hline 10 & 565,40 & 0,520 \\
\hline 11 & 572,00 & 0,505 \\
\hline 12 & 586,20 & 0,501 \\
\hline
\end{tabular}

Penentuan panjang gelombang maksimum larutan seri konsentrasi baku natrium nitrit $0,7 \mathrm{ppm}$ diukur pada rentang panjang gelombang 490-590 $\mathrm{nm}$, kemudian diambil panjang gelombang yang menghasilkan absorbansi terbesar. Dari hasil pengukuran diperoleh panjang gelombang maksimum 543,8 nm yang menghasilkan absorbansi terbesar, yaitu 0,740 .

\section{Hasil Penentuan Operating Time}

Setelah penentuan panjang gelombang maksimum perlu dilakukan penentuan operating time untuk mengetahui waktu yang dibutuhkan oleh larutan uji untuk mencapai absorbansi yang konstan atau pengukuran yang stabil. Penentuan operating time dilakukan dengan mengukur hubungan antara waktu pengukuran dengan absorbansi larutan baku(15).

Tabel 2. Hasil penentuan operating time larutan seri konsentrasi baku natrium nitrit $0,7 \mathrm{ppm}$

\begin{tabular}{|c|c|c|}
\hline No & Waktu (menit) & Absorbansi \\
\hline 1 & 6 & 0,736 \\
\hline 2 & 9 & 0,729 \\
\hline 3 & $\mathbf{1 2}$ & $\mathbf{0 , 7 3 0}$ \\
\hline 4 & 15 & 0,730 \\
\hline 5 & 18 & 0,736 \\
\hline
\end{tabular}

Penentuan operating time dilakukan dengan mengukur absorbansi larutan seri konsentrasi baku natrium nitrit 0,7 ppm pada panjang gelombang yang telah ditentukan, yaitu $543,8 \mathrm{~nm}$ pada rentang waktu menit ke-6,9,12,15 dan 18. Dari hasil pengukuran diperoleh absorbansi konstan pada menit ke-12 sampai menit ke-15, yaitu sebesar 0,730 sehingga diperoleh operating time nya pada menit ke-12. 


\section{Hasil Uji Parameter Ketelitian atau Keseksamaan (Precision)}

Pengujian parameter ketelitian atau keseksamaan (precision) pada penelitian ini dilakukan terhadap sampel A sebanyak enam kali pengulangan. Syarat suatu metode memiliki ketelitian yang baik jika nilai $\mathrm{RSD} \leq 2 \%(8)$.

Tabel 3. Hasil pengukuran uji ketelitian (precision) sampel $\mathrm{A}$

\begin{tabular}{|c|c|c|}
\hline Ulangan & $\begin{array}{c}\text { Konsentrasi } \\
(\mathbf{X i})\end{array}$ & $\begin{array}{c}\text { Absorbansi } \\
(\mathbf{Y})\end{array}$ \\
\hline 1 & 0,228 & 0,247 \\
\hline 2 & 0,230 & 0,249 \\
\hline 3 & 0,232 & 0,251 \\
\hline 4 & 0,235 & 0,254 \\
\hline 5 & 0,229 & 0,248 \\
\hline 6 & 0,234 & 0,253 \\
\hline Jumlah & 1,388 & 1,502 \\
\hline Rata-rata & 0,231 & 0,250 \\
\hline SD & \multicolumn{3}{|c|}{0,0028} \\
\hline RSD (\%) & \multicolumn{3}{|c}{1,2121} \\
\hline
\end{tabular}

Berdasarkan data diatas, diperoleh nilai simpangan baku atau standar deviasi (SD) sebesar 0,0028 dan nilai koefisien variasi atau simpangan baku relatif (RSD) sebesar $1,2121 \%$. Hal ini menunjukkan bahwa metode yang digunakan dalam analisis ini memiliki ketelitian (precision) yang baik.

\section{Hasil Uji Parameter Linieritas (Linearity) dan Rentang (Range) serta Pembuatan Kurva Kalibrasi dan Penentuan Persamaan Regresi Linier}

Uji linieritas dan rentang pada penelitian ini dilakukan dengan membuat larutan seri konsentrasi baku natrium nitrit dengan konsentrasi 0,$0 ; 0,1 ; 0,2 ; 0,3 ; 0,4 ; 0,5 ; 0,6$; 0,$7 ; 0,8 ; 0,9 ; 0,9$; dan $1 \mathrm{ppm}$, kemudian masing-masing larutan seri konsentrasi baku tersebut diukur absorbansinya pada panjang gelombang maksimum $543,8 \mathrm{~nm}$ dan operating time menit ke-12. Hasil dari pengukuran nilai absorbansi larutan seri konsentrasi baku natrium nitrit tersebut digunakan untuk membuat kurva kalibrasi. Kurva kalibrasi digunakan untuk menentukan linieritas garis, rentang pengukuran dan persamaan regresi linier(15).

Penentuan linieritas garis persamaan regresi linier diperoleh dengan menghitung nilai koefisien korelasi $(r)$ dan koefisien determinasi $\left(R^{2}\right)$. Syarat linieritas garis yang sangat baik jika nilai $r>0,999$ dan nilai $R^{2}>0,997(8)$.

Jika semua data digunakan untuk membuat kurva baku, maka nilai koefisien korelasi $(r)$ yang diperoleh sebesar 0,9728 dan nilai koefisien determinasi $\left(R^{2}\right)$ sebesar 0,9463 sehingga tidak memenuhi syarat linieritas garis yang baik, dimana nilai $(r)$ dan $\left(R^{2}\right)$ harus sangat mendekati 1(8). Untuk mendapatkan nilai $(r)$ dan $\left(R^{2}\right)$ yang sangat mendekati 1 , maka harus dibuang data yang menyebabkan kurva baku tidak linier, yaitu data larutan seri konsentrasi baku 0,8-1,0 ppm.

Tabel 5. Hasil pengukuran nilai absorbansi larutan seri konsentrasi baku natrium nitrit $0,0-0,7 \mathrm{ppm}$

\begin{tabular}{|c|c|c|}
\hline No & $\begin{array}{c}\text { Konsentrasi } \\
\text { (ppm) }\end{array}$ & Absorbansi \\
\hline 1 & 0,000 & 0,004 \\
\hline 2 & 0,100 & 0,113 \\
\hline 3 & 0,200 & 0,221 \\
\hline 4 & 0,300 & 0,316 \\
\hline 5 & 0,400 & 0,426 \\
\hline 6 & 0,500 & 0,548 \\
\hline 7 & 0,600 & 0,639 \\
\hline 8 & 0,700 & 0,743 \\
\hline$r$ & & 0,9997 \\
\hline$R^{2}$ & & 0,9994 \\
\hline$b$ & \multicolumn{2}{c}{1,0588} \\
\hline$a$ & \multicolumn{2}{c}{0,0057} \\
\hline
\end{tabular}

Kulva Baku Natrium Nitrit

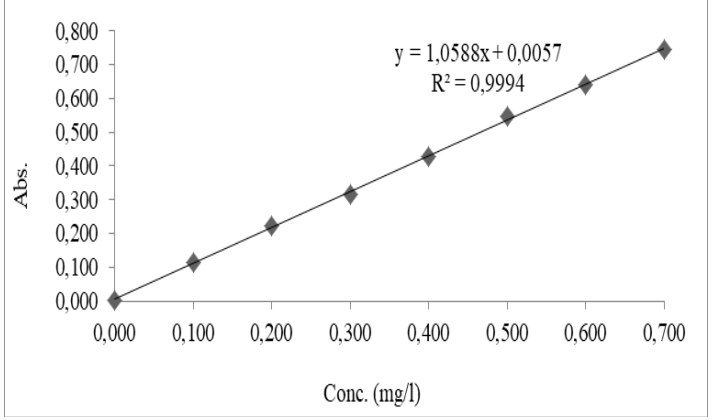


Gambar 2. Kurva baku natrium nitrit $0,0-0,7$ ppm

Setelah dilakukan perhitungan diperoleh nilai koefisien korelasi $(r)=0,9997$, koefisien determinasi $\left(R^{2}\right)=0,9994$, kemiringan garis/slope $(b)=1,0588$ dan nilai konstanta/intersep (a) $=0,0057$ sehingga diperoleh persamaan regresi regresi linier $y=1,0588 x+0,0057$. Nilai dari koefisien korelasi $(r)>0,999$ dan nilai koefisien determinasi $\left(R^{2}\right)>0,997$ menunjukkan linieritas yang sangat baik(7). Hal ini menunjukkan bahwa persamaan regresi linier diatas dapat digunakan untuk menentukan konsentrasi natrium nitrit dalam sampel uji.

\section{Hasil Uji Parameter Ketepatan (Accuracy)}

Pengujian parameter ketepatan (accuracy) pada penelitian ini dilakukan terhadap sampel A yang ditambahkan larutan adisi standar natrium nitrit dalam 5 konsentrasi yang berbeda, yaitu larutan adisi standar natrium nitrit 50\% (0,15 ppm), 75\% (0,225 ppm), 100\% (0,3 ppm), 125\% (0,375 ppm) dan $150 \% \quad(0,45 \mathrm{ppm})$. Syarat suatu metode memiliki ketepatan yang baik jika diperoleh nilai persen perolehan kembali larutan adisi standar yang ditambahkan berkisar antara $98-102 \%(8)$.

Tabel 6. Hasil pengukuran uji ketepatan (accuracy) sampel A

\begin{tabular}{|c|c|c|c|c|}
\hline No & $\begin{array}{c}\text { Identitas } \\
\text { Sampel }\end{array}$ & $\mathbf{X}$ & $\mathbf{Y}$ & $\begin{array}{c}\text { Persen } \\
\text { Recovery } \\
\text { (\%) }\end{array}$ \\
\hline 1 & $\mathrm{~A} 1+\mathrm{AS} 50 \%$ & 0,2568 & 0,2776 & 98,630 \\
\hline 2 & $\mathrm{~A} 2+\mathrm{AS} 75 \%$ & 0,2729 & 0,2946 & 99,550 \\
\hline 3 & $\mathrm{~A} 3+\mathrm{AS} \mathrm{100 \%}$ & 0,2868 & 0,3094 & 99,830 \\
\hline 4 & $\mathrm{~A} 4+\mathrm{AS} 125 \%$ & 0,3044 & 0,3280 & 100,800 \\
\hline 5 & A5 + AS 150\% & 0,3178 & 0,3422 & 101,240 \\
\hline
\end{tabular}

Ket: AS : Adisi standar

Berdasarkan data pada tabel diatas, dapat diketahui bahwa nilai terkecil persen perolehan kembali (\% recovery) yang diperoleh dari pengukuran, yaitu sebesar $98,630 \%$ dan nilai tertinggi persen perolehan kembali (\% recovery) yang diperoleh sebesar $101,240 \%$. Nilai persen perolehan kembali (\% recovery) yang diperoleh berada dalam rentang yang disyaratkan, yaitu berkisar antara 98$102 \%$. Hal ini menunjukkan bahwa metode yang digunakan dalam analisis ini memiliki ketepatan (accuracy) yang baik.

\section{Hasil Uji Parameter Batas Deteksi (Limit of Detection) dan Batas Kuantitasi (Limit of Quantitation)}

Penentuan batas deteksi (limit of detection) dan batas kuantitasi (limit of quantitation) dihitung dari data kurva kalibrasi larutan seri konsentrasi baku natrium nitrit 0,0-0,7 ppm. Jika konsentrasi analit dalam sampel melebihi nilai batas deteksi dan batas kuantitasi maka seluruh sampel dapat terdeteksi serta dapat memberikan ketepatan dan ketelitian atau keseksamaan analisis(8).

Tabel 7. Hasil perhitungan nilai batas deteksi dan batas kuantitasi larutan seri konsentrasi baku natrium nitrit

\begin{tabular}{|c|c|c|}
\hline No & $\begin{array}{c}\text { Konsentrasi } \\
(\mathbf{X})\end{array}$ & $\begin{array}{c}\text { Absorbansi } \\
(\mathbf{Y})\end{array}$ \\
\hline 1 & 0,000 & 0,004 \\
\hline 2 & 0,100 & 0,113 \\
\hline 3 & 0,200 & 0,221 \\
\hline 4 & 0,300 & 0,316 \\
\hline 5 & 0,400 & 0,426 \\
\hline 6 & 0,500 & 0,548 \\
\hline 7 & 0,600 & 0,639 \\
\hline 8 & 0,700 & 0,743 \\
\hline$S_{y / x}$ & \multicolumn{3}{|c}{0,0066} \\
\hline LOD & \multicolumn{3}{|c}{0,0187} \\
\hline LOQ & \multicolumn{3}{|c}{} \\
\hline
\end{tabular}

Berdasarkan data pada tabel diatas, dapat diketahui bahwa nilai batas deteksi dan batas kuantitasi pengukuran yang diperoleh sebesar 0,0187 ppm dan 0,0623 ppm, artinya pada konsentrasi tersebut sampel masih dapat dideteksi dengan baik dan memberikan hasil pengukuran yang teliti dan akurat. 


\section{Hasil Analisis Kadar Nitrit Dalam Sampel}

Prinsip penetapan kadar nitrit dalam sampel didasarkan pada reaksi diazotasi antara asam nitrit (dari nitrit dalam suasana asam) dengan amin aromatis primer (sulfanilamid) membentuk garam diazonium. Garam diazonium yang dihasilkan dari reaksi tersebut kemudian direaksikan kembali dengan naftiletilendiamin membentuk senyawa berwarna yang dapat diukur pada rentang panjang gelombang 400-600 $\mathrm{nm}(16)$.

Dari hasil pengukuran nilai absorbansi sampel dapat ditentukan besarnya konsentrasi natrium nitrit dalam sampel, dihitung dengan persamaan regresi linier $y=1,0588 x+0,0057$

Tabel 8. Hasil perhitungan konsentrasi natrium nitrit dalam sampel

\begin{tabular}{|c|c|c|c|c|}
\hline No & $\begin{array}{c}\text { Identitas } \\
\text { Sampel }\end{array}$ & Ulangan & Absorbansi & $\begin{array}{c}\mathrm{C} \\
(\mathrm{mg} / \mathrm{L})\end{array}$ \\
\hline \multirow{3}{*}{1} & \multirow{3}{*}{ A } & A1 & 0,247 & 0,228 \\
\hline & & $\mathrm{A} 2$ & 0,390 & 0,363 \\
\hline & & $\mathrm{A} 3$ & 0,294 & 0,272 \\
\hline \multirow{3}{*}{2} & \multirow{3}{*}{ B } & B1 & 0,164 & 0,149 \\
\hline & & B2 & 0,189 & 0,173 \\
\hline & & B3 & 0,116 & 0,104 \\
\hline \multirow{3}{*}{3} & \multirow{3}{*}{ C } & $\mathrm{C} 1$ & 0,632 & 0,592 \\
\hline & & $\mathrm{C} 2$ & 0,712 & 0,667 \\
\hline & & $\mathrm{C} 3$ & 0,605 & 0,566 \\
\hline \multirow{3}{*}{4} & \multirow{3}{*}{ D } & $\mathrm{D} 1$ & 0,526 & 0,491 \\
\hline & & $\mathrm{D} 2$ & 0,558 & 0,522 \\
\hline & & D3 & 0,522 & 0,488 \\
\hline \multirow{3}{*}{5} & \multirow{3}{*}{$\mathrm{E}$} & E1 & 0,141 & 0,128 \\
\hline & & E2 & 0,163 & 0,149 \\
\hline & & E3 & 0,162 & 0,148 \\
\hline \multirow{3}{*}{6} & \multirow{3}{*}{$\mathrm{F}$} & $\mathrm{F} 1$ & 0,148 & 0,135 \\
\hline & & $\mathrm{F} 2$ & 0,152 & 0,138 \\
\hline & & F3 & 0,132 & 0,119 \\
\hline
\end{tabular}

Tabel 9. Hasil perhitungan kadar nitrit dalam sampel

\begin{tabular}{|c|c|c|c|c|}
\hline No & $\begin{array}{c}\text { Identitas } \\
\text { Sampel }\end{array}$ & Ulangan & $\begin{array}{c}\text { Kadar Nitrit } \\
(\mathbf{m g} / \mathbf{k g})\end{array}$ & $\begin{array}{c}\text { Kadar } \\
\text { Rata-Rata } \\
\text { Nitrit } \\
(\mathbf{m g} / \mathbf{k g})\end{array}$ \\
\hline 1 & A & A1 & 15,095 & 18,963 \\
\hline
\end{tabular}

\begin{tabular}{|c|c|c|c|c|}
\hline & & A2 & 23,821 & \\
\hline & & $\mathrm{A} 3$ & 17,974 & \\
\hline \multirow{3}{*}{2} & \multirow{3}{*}{ B } & B1 & 9,904 & \multirow{3}{*}{9,427} \\
\hline & & B2 & 11,443 & \\
\hline & & B3 & 6,934 & \\
\hline \multirow{3}{*}{3} & \multirow{3}{*}{ C } & $\mathrm{C} 1$ & 39,360 & \multirow{3}{*}{40,407} \\
\hline & & $\mathrm{C} 2$ & 44,215 & \\
\hline & & $\mathrm{C} 3$ & 37,647 & \\
\hline \multirow{3}{*}{4} & \multirow{3}{*}{ D } & D1 & 32,704 & \multirow{3}{*}{33,181} \\
\hline & & $\mathrm{D} 2$ & 34,316 & \\
\hline & & D3 & 32,523 & \\
\hline \multirow{3}{*}{5} & \multirow{3}{*}{$E$} & E1 & 8,522 & \multirow{3}{*}{9,423} \\
\hline & & E2 & 9,900 & \\
\hline & & E3 & 9,847 & \\
\hline \multirow{3}{*}{6} & \multirow{3}{*}{$\mathrm{F}$} & F1 & 8,976 & \multirow{3}{*}{8,689} \\
\hline & & $\mathrm{F} 2$ & 9,166 & \\
\hline & & F3 & 7,925 & \\
\hline
\end{tabular}

Dari 6 sampel yang dianalisis dengan 3 kali pengulangan, diperoleh kadar nitrit yang berbeda pada masing-masing sampel, terdapat 2 sampel yang mengandung pengawet nitrit melebihi batas maksimum yang diizinkan sesuai dengan peraturan Kepala BPOM RI No. 36 tahun 2013. Kedua sampel tersebut adalah sampel yang diperoleh dari Pasar Panjang (Sampel C) dengan kadar ratarata nitrit sebesar 40,407 $\mathrm{mg} / \mathrm{kg}$ dan sampel yang diperoleh dari Pasar Tugu (Sampel D) dengan kadar rata-rata nitrit sebesar 33,181 mg/kg, sedangkan empat sampel lainnya, yaitu sampel yang diperoleh dari Pasar Koga (Sampel A), sampel yang diperoleh dari Pasar Ambon (Sampel B), sampel yang diperoleh dari Pasar Perumnas Way Halim (Sampel E) dan sampel yang diperoleh dari Pasar Tempel Way Dadi (Sampel F) mengandung nitrit yang tidak melebihi batas maksimumyang diizinkan dengan kadar rata-rata, yaitu $18,963 \mathrm{mg} / \mathrm{kg}, 9,427$ $\mathrm{mg} / \mathrm{kg}, 9,423 \mathrm{mg} / \mathrm{kg}$ dan $8,689 \mathrm{mg} / \mathrm{kg}$.

Sampel $C$ dan $D$ memiliki kadar nitrit yang lebih besar dan memiliki warna merah yang lebih terang dan menarik dibandingkan dengan sampel $A, B, E$ dan $F$ yang memiliki warna merah yang pudar bahkan cenderung kecoklatan. Hal ini berbanding lurus dengan fungsi nitrit lainnya bahwa selain sebagai pengawet, nitrit juga berfungsi untuk 
mempertahankan warna merah daging agar tetap stabil sehingga tetap terlihat segar pada saat daging diolah. Oleh karena itu, perlu diwaspadai jika sosis sapi yang akan dikonsumsi memiliki warna merah yang sangat terang dan terlihat lebih menarik karena berkemungkinan besar mengandung nitrit melebihi batas maksimum yang diizinkan(2).

Hasil analisis kuantitatif nitrit pada sampel menunjukkan bahwa tidak semua sampel mengandung nitrit melebihi batas maksimum yang diizinkan, akan tetapi mengkonsumsi sosis sapi yang mengandung pengawet nitrit perlu dibatasi karena nitrit bersifat kumulatif dalam tubuh manusia jika dikonsumsi secara terus menerus sehingga kadarnya akan terus bertambah dalam tubuh manusia dan berpotensi menimbulkan kanker(5).

Berdasarkan uraian diatas, untuk menghindari efek toksik dari nitrit maka seharusnya kita lebih selektif dan teliti dalam memilih makanan-makanan yang terbuat dari olahan daging yang akan dikonsumsi agar terhindar dari dampak negatif dari pengawet nitrit tersebut, karena tidak hanya sosis sapi yang mengandung pengawet nitrit namun bisa juga berasal dari makanan-makanan lain yang terbuat dari olahan daging, seperti abon sapi, kornet sapi, daging burger, daging kebab, dan lain-lain.

\section{KESIMPULAN DAN SARAN}

\section{KESIMPULAN}

Berdasarkan hasil penelitian yang dilakukan tentang analisis kadar nitrit pada sosis sapi kemasan yang beredar di pasar tradisional Bandar Lampung secara spektrofotometri uv-vis dapat disimpulkan bahwa:

1. Metode spektrofotometri uv-vis layak dijadikan sebagai metode uji pada analisis kadar nitrit yang terkandung dalam sosis sapi kemasan yang beredar di pasar tradisional Kota Bandar Lampung.
2. Terdapat 2 sampel yang mengandung nitrit melebihi batas maksimum yang diizinkan, yaitu sampel dari Pasar Panjang (sampel C) $=40,407 \mathrm{mg} / \mathrm{kg}$ dan sampel dari Pasar Tugu (sampel D) $=33,181 \mathrm{mg} / \mathrm{kg}$ sesuai dengan peraturan Kepala BPOM RI No.36 tahun 2013 tentang batas maksimum penggunaan bahan tambahan pangan pengawet nitrit pada produk-produk olahan daging, daging unggas dan daging hewan buruan yang dihaluskan, yaitu tidak lebih dari 30 $\mathrm{mg} / \mathrm{kg}$, sedangkan 4 sampel lainnya, yaitu sampel dari Pasar Koga (sampel A) $=18,963 \mathrm{mg} / \mathrm{kg}$, sampel dari Pasar Ambon (sampel B) $=9,427 \mathrm{mg} / \mathrm{kg}$, sampel dari Pasar Perumnas Way Halim (sampel E)=9,423 $\mathrm{mg} / \mathrm{kg}$ dan sampel dari pasar Tempel Way Dadi (sampel $\quad \mathrm{F}$ ) $=8,689 \quad \mathrm{mg} / \mathrm{kg}$ mengandung nitrit yang tidak melebihi batas maksimum yang diizinkan.

\section{SARAN}

Kepada peneliti selanjutnya disarankan untuk melakukan penelitian tentang analisis kadar logam berat dan cemaran mikroba pada sosis sapi yang beredar di pasar tradisional Kota Bandar Lampung.

\section{UCAPAN TERIMAKASIH}

Terima kasih kepada Unit Pelaksana Teknis Dinas (UPTD) Balai Laboratorium Kesehatan Provinsi Lampung yang telah memberikan izin penelitian kepada penulis, dan FMIPA Program Studi Farmasi Universitas Tulang Bawang Lampung

\section{DAFTAR PUSTAKA}

[1]. Aisya RW. Hubungan kebiasaan konsumsi makanan cepat saji dengan kejadian penyakit jantung koroner pada pasien rawat jalan di RSUD DR.MOEWARDI Surakarta. Fakultas IImu Kesehatan Universitas Muhammadiyah Surakarta. 2015. hlm.7. 
[2]. Nur HH, Suryani D. Analisis kandungan nitrit dalam sosis pada distributor sosis di Kota Yogyakarta. Kes Mas. 2012;6(1):2.

[3]. Soeparno. 2015. Ilmu dan teknologi daging. Edisi II. Yogyakarta: Gadjah Mada University Press.hlm.271272,309-322.

[4]. Departemen Kesehatan Republik Indonesia. 2013. Peraturan Kepala Badan Pengawasan Obat dan Makanan Republik Indonesia Nomor 36 Tahun 2013 tentang batas maksimum penggunaan bahan tambahan pangan pengawet. Jakarta: Direktorat Jendral Pengawasan Obat dan Makanan.hlm.22-23.

[5]. Cahyadi W. 2012. Analisis dan aspek kesehatan bahan tambahan pangan. Edisi II. Jakarta: Bumi aksara.hlm.7-10,28-29.

[6]. Defayanti Suci, Nasution E, Aritonang EY. Analisis kandungan nitrit pada sosis bermerek dan tidak bermerek di Kota Medan 2016. Jurnal.usu.ac.id. 2017;1(1):5.

[7]. Romsiah, Sintya LM, Ahmad F. Validasi metode dan penetapan kadar nitrit $\left(\mathrm{NO}_{2}\right)$ pada sosis sapi curah dan sosis sapi kaleng yang dijual di swalayan Kota Palembang secara spektrofotometri uv-vis. Scientia. 2017;(2):113-119.

[8]. Riyanto. 2014. Validasi dan verifikasi metode uji. Yogyakarta: CV.Budi Utama.hlmn.9-78.

[9]. Heru Kasjono Subaris, Yasril. 2009. Teknik sampling untuk penelitian kesehatan. Yogyakarta: Graha IImu.hlmn.13.

[10]. Lestari P, Sabikis, Utami PI. Analisis natrium nitrit secara spektrofotometri visible dalam daging burger yang beredar di swalayan Purwokerto.Jurnal Pharmacy. 2011;8(3):88-98.

[11]. Rusdi, Zulharmita, Nurrohmah IS. Analisis pengawet nitrit pada daging sapi dengan spektrofotometri uv-vis. Jurnal Farmasi Higea. 2015;7(1):101-110.

[12]. Badan Standardisasi Nasional. 1992. SNI 01-2894-1992 Cara uji bahan pengawet pada makanan dan bahan tambahan pangan yang dilarang untuk makanan. Jakarta: Dewan Standardisasi Nasional.hlm 11-12.

[13]. Harmita. Petunjuk pelaksanaan validasi metode dan cara perhitungannya. Majalah ilmu kefarmasian. 2004;1(3):117-135.

[14]. Association of Official Analitycal Chemistry. AOAC determination of manual of methods of analysis food meat and meat product and fish product. New Delhi: Chapter 6. 2012.p.3-9.

[15]. Lukas JA, Abidjulu J, Yamlean P. Analisis kandungan natrium nitrit pada ayam crispy di Kota Manado. Pharmacon Jurnal IImiah FarmasiUNSRAT. 2016;5(4):182-191.

[16]. Rohman A. 2011. Analisis bahan pangan. Yogyakarta: Pustaka Pelajar.hlmn.205-209. 